\title{
Efficacy of a coating composed of chitosan from Mucor circinelloides and carvacrol to control Aspergillus flavus and the quality of cherry tomato fruits
}

OPEN ACCESS

Edited by:

Sahdeo Prasad,

The University of Texas MD Anderson

Cancer Center, USA

Reviewed by:

Davide Gottardi,

ProDigest, Belgium

Awanit Kumar,

Atlantic Cancer Research Institute,

Canada

Shivani Agarwal,

Northwestern University, USA

*Correspondence:

Evandro L. de Souza,

Laboratório de Microbiologia de

Alimentos, Departamento de Nuttrição, Centro de Ciências da

Saúde, Universidade Federal da

Paraíba, Campus I, Cidade

Universitária, 58051-900

João Pessoa, Paraíba, Brazil evandroleitesouza@ccs.ufpb.br

Specialty section:

This article was submitted to

Food Microbiology,

a section of the journal

Frontiers in Microbiology

Received: 28 May 2015

Accepted: 03 July 2015

Published: 20 July 2015

Citation:

de Souza EL, Sales CV,

de Oliveira CEV, Lopes LAA,

da Conceição ML, Berger LRR

and Stamford TCM (2015) Efficacy

of a coating composed of chitosan

from Mucor circinelloides

and carvacrol to control Aspergillus

flavus and the quality of cherry tomato

fruits.

Front. Microbiol. 6:732.

doi: 10.3389/fmicb.2015.00732
Evandro L. de Souza ${ }^{1 *}$, Camila V. Sales ${ }^{1}$, Carlos E. V. de Oliveira ${ }^{1}$, Laênia A. A. Lopes ${ }^{1}$, Maria L. da Conceição ${ }^{1}$, Lúcia R. R. Berger ${ }^{1}$ and Thayza C. M. Stamford ${ }^{2}$

' Laboratório de Microbiologia de Alimentos, Departamento de Nuttrição, Centro de Ciências da Saúde, Universidade Federal da Paraíba, João Pessoa, Brazil, ${ }^{2}$ Laboratório de Microbiologia, Departamento de Medicina Tropical, Centro de Ciências da Saúde, Unversidade Federal de Pernambuco, Recife, Brazil

Cherry tomato (Lycopersicon esculentum Mill) fruits are susceptible to contamination by Aspergillus flavus, which may cause the development of fruit rot and significant postharvest losses. Currently there are significant drawbacks for the use of synthetic fungicides to control pathogenic fungi in tomato fruits, and it has increased the interest in exploring new alternatives to control the occurrence of fungal infections in these fruits. This study evaluated the efficacy of chitosan (CHI) from Mucor circinelloides in combination with carvacrol (CAR) in inhibiting $A$. flavus in laboratory media and as a coating on cherry tomato fruits $\left(25^{\circ} \mathrm{C}, 12\right.$ days and $12^{\circ} \mathrm{C}, 24$ days). During a period of storage, the effect of coatings composed of $\mathrm{CHI}$ and $\mathrm{CAR}$ on autochthonous microflora, as well as on some quality characteristics of the fruits such as weight loss, color, firmness, soluble solids, and titratable acidity was evaluated. $\mathrm{CHI}$ and CAR displayed MIC valuesof $7.5 \mathrm{mg} / \mathrm{mL}$ and $10 \mu \mathrm{L} / \mathrm{mL}$, respectively, against $A$. flavus. The combined application of $\mathrm{CHI}(7.5$ or $3.75 \mathrm{mg} / \mathrm{mL}$ ) and CAR (5 or $2.5 \mu \mathrm{L} / \mathrm{mL}$ ) strongly inhibited the mycelial growth and spore germination of $A$. flavus. The coating composed of $\mathrm{CHI}$ ( $3.75 \mathrm{mg} / \mathrm{mL}$ ) and CAR (2.5 or $1.25 \mu \mathrm{L} / \mathrm{mL}$ ) inhibited the growth of $A$. flavus in artificially contaminated fruits, as well as the native fungal microflora of the fruits stored at room or low temperature. The application of the tested coatings preserved the quality of cherry tomato fruits as measured by some physicochemical attributes. From this, composite coatings containing $\mathrm{CHI}$ and $\mathrm{CAR}$ offer a promising alternative to control postharvest infection caused by $A$. flavus or native fungal microflora in fresh cherry tomato fruits without negatively affecting their quality over storage.

Keywords: Aspergillus, Lycopersicon esculentum Mill, fungi chitosan, phenolic compound, postharvest treatment

\section{Introduction}

In recent years, the population has shown more interest in acquiring a good quality of life including a balanced diet, which requires a regular consumption of fresh fruits and vegetables. Cherry tomato (Lycopersicon esculentum Mill) fruits are of great importance in many countries for economic purposes (Guo et al., 2014; Quiao et al., 2015), with a global production of fresh tomato fruits 
near 35,000 tons/year. The global consumption of tomato products is near 31,000 tons/year, with an average annual per capita consumption of $\sim 6 \mathrm{~kg} /$ inhabitant and fresh fruits represent near $75 \%$ of this consumption (World Processing Tomato Council [WPTC], 2010). However, these fruits are susceptible to various forms of contamination by phytopathogen agents during production, handling, distribution and storage. This contamination can limit their shelf life of tomato fruits and cause postharvest losses as high as $40 \%$ in less industrialized countries (Liu et al., 2007; Ramos-García et al., 2012).

Aspergillus flavus is among the most common pathogenic fungi affecting cherry tomato fruits, and it grows over the fruit surface, causing losses and decay (Aspergillus rot; Tian et al., 2011; Tijjani et al., 2014a,b) and producing an aflatoxin that is a genotoxic, immunotoxic and hepatocarcinogenic secondary metabolite to human beings (Tian et al., 2015). Although synthetic chemical fungicides are the primary means to control populations of pathogenic fungi and related-postharvest diseases in tomato fruits (Sánchez-Domínguez et al., 2011; Chen et al., 2014), their use presents drawbacks in respect to handling hazards, awareness about fungicides residues on food and risks to human health and environment (Soylu et al., 2010). Thus, it has impelled the interest in exploring new alternatives to decrease the use of synthetic fungicides in tomato fruits (Feng et al., 2011). In this context, edible coatings composed of chitosan (CHI) and essential oils or their individual constituents have recently been considered as an environmentally friendly technology to control postharvest decay because of their biodegradability and the lack of phytotoxicity (dos Santos et al., 2012; Beyki et al., 2014).

Chitosan is a deacetylated derivative of chitin. Both $\mathrm{CHI}$ and chitin are natural co-polymers, comprising units of 2-amino-2-deoxy-D-glycopyranose and 2-acetamide-2-deoxyD-glycopyranose interconnected by glycosidic $\beta-1,4$ bonds (Coqueiro et al., 2011). The 2-amino-2-deoxy-D-glycopyranose is more frequently observed in CHI (Berger et al., 2014; de Oliveira et al., 2014a). The polymer CHI is a biodegradable non-toxic compound and potential fungicide considered for use in fresh fruits and vegetables due to its biochemical and excellent semipermeable film-forming properties (Aloui et al., 2014; Chen et al., 2014).

Although the primary commercial source of CHI has been crustacean shells, the fungal production of high-quality $\mathrm{CHI}$ by fermentation technology has been heavily exploited due to the great advantages of CHI such as independence from seasonal factors, ability to be produced on a wide scale and simultaneous chitin and CHI extraction (de Oliveira et al., 2014a,b). Moreover, this strategy of producing $\mathrm{CHI}$ by fermentation technology avoids protein contamination that could cause allergic reactions in individuals with shellfish allergies (Berger et al., 2014). Obtaining CHI from fungi is known to be a simple process that is economically and environmentally viable, especially when biowaste from an industrial activity, such as production of corn steep liquor (CSL), is used as nutritional source in media culture for cultivation of fungi (Berger et al., 2014). In a previous study, Mucor circinelloides (Mucorales order, Zygomycetes class) showed a level of high $\mathrm{CHI}$ production when cultivated in CSL-based media (de Oliveira et al., 2014b).

Coatings composed of $\mathrm{CHI}$ and other active substances have presented efficacy for inhibiting the growth of phytopathogenic fungi on different fruits (dos Santos et al., 2012; Beyki et al., 2014). Studies have demonstrated strong and wide-spectrum inhibitory effects of different essential oil constituents against food-related pathogenic fungi (Tao et al., 2014). From these studies, the phenolic carvacrol (CAR), primarily related to the antimicrobial property of different essential oils, has emerged as a potent growth inhibitor for different fungi (Feng and Zeng, 2007). However, CAR has still not been rationally exploited as an anti-postharvest pathogenic fungi compound when applied either in free-form or as a component of coating materials. CAR appears to have either no significant or marginal toxic effects in vivo and raises no concerns regarding the possible level of use in foods (Pharmaceutical Codex, 1979; Burt, 2004). Although early studies have focused on the antimicrobial activity of crustacean CHI toward different postharvest fungi (Badawy and Rabea, 2009; Ramos-García et al., 2012), there is limited knowledge about the effects of fungal $\mathrm{CHI}$ alone or in combination with other antimicrobial compounds on inhibition of postharvest pathogenic fungi in fruits.

Considering these aspects, this study assessed the efficacy of the combined application of $\mathrm{CHI}$ from $M$. circinelloides and CAR as a postharvest treatment to prevent $A$. flavus infections in cherry tomato fruits. For this, assays were performed to (1) determine the minimum inhibitory concentration (MIC) of $\mathrm{CHI}$ and CAR, (2) evaluate the inhibitory effects of different combinations of these substances at subinhibitory concentrations on A. flavus in laboratory media and forming different coatings on cherry tomato fruits and (3) verify the effects of the tested coatings on the physicochemical characteristics of cherry tomato fruits during storage.

\section{Materials and Methods}

\section{Raw Materials}

Cherry tomato (Lycopersicon esculentum Mill) fruits were purchased from a local wholesale distributor and selected for uniform characteristics (size, form, appearance and red color) and absence of visible infection signs and/or mechanical injuries (Aloui et al., 2014). Before assays with artificially contaminated fruits and for evaluation of physicochemical quality parameters, the tomato fruits were surface-disinfected by immersion in a sodium hypochlorite solution (150 ppm, pH 7.2 adjusted with $1 \mathrm{M} \mathrm{NaOH}$ ) for $15 \mathrm{~min}$, washed using sterile distilled water and air-dried for $2 \mathrm{~h}$ in a bio-safety cabinet (de Oliveira et al., 2014a,b).

Corn steep liquor used as the substrate for the growth of M. circinelloides UCP 050 was obtained from a Brazilian corn processing company (Produtos de Milho, Ltd., Cabo de Santo Agostinho, Brazil). CAR was obtained from Sigma Aldrich (Sigma, France). M. circinelloides UCP 050, used for CHI production, was gently supplied from the Culture Collection 
of the Catholic University of Pernambuco (Recife, Brazil). A. flavus URM 4550 was obtained from the University of Recife Mycology Culture Collection (Center for Biological Sciences, Federal University of Pernambuco, Recife, Brazil). This strain was verified for their ability to cause rot in cherry tomato fruits. Continuous procedures of re-inoculations and re-isolations on cherry tomato fruits were performed to maintain the capability of the test A. flavus strain to cause fruit rot (Sánchez-Domínguez et al., 2011). For assays, stock cultures were subcultured in Sabouraud agar (Himedia, India) at $28^{\circ} \mathrm{C}$ for 7 days to reach sufficient sporification (de Oliveira et al., 2014a,b).

\section{Production of Chitosan}

The production of CHI was carried out by submerged cultivation of $M$. circinelloides UCP 050 in a CSL-based medium (7 g CSL/100 mL; pH 5.5 adjusted using $0.1 \mathrm{M} \mathrm{HCl}, 150 \mathrm{rpm}$, for $72 \mathrm{~h}$ at $25^{\circ} \mathrm{C}$ ) according to a previously described procedure (de Oliveira et al., 2014b). CHI showed a degree of deacetylation of $82 \%$ and a characteristic thermal degradation pattern and diffraction peaks (de Oliveira et al., 2014b). The CHI (in powder form) was stored at $-20^{\circ} \mathrm{C}$.

\section{Preparation of $\mathrm{CHI}$ and CAR Solutions and Coatings}

The different $\mathrm{CHI}$ solutions were obtained by dissolution of the polymer $(20 \mathrm{mg} / \mathrm{mL})$ in acetic acid $(1 \mathrm{~mL} / 100 \mathrm{~mL}, \mathrm{pH} 5.6)$ during $24 \mathrm{~h}$ at room temperature (RT) under stirring $(120 \mathrm{rpm}$; dos Santos et al., 2012). Serial dilutions (1:1) were carried out using Sabouraud broth (Himedia, India) to obtain solutions with $\mathrm{CHI}$ concentrations varying from 15 to $0.12 \mathrm{mg} / \mathrm{mL}$. To ensure that the observed fungi inhibition was due to the tested $\mathrm{CHI}$ and not to acetic acid used in solutions preparation, the $\mathrm{pH}$ of all $\mathrm{CHI}$ solutions was adjusted to 5.6 using $3 \mathrm{M} \mathrm{NaOH}$. Preliminary experiments showed that the acetic acid solution at $\mathrm{pH} \geq 5.6$ did not inhibit the growth of the fungi tested strain (de Oliveira et al., 2014a,b). The CAR solutions (10-0.06 $\mu \mathrm{L} / \mathrm{mL})$ were prepared in Sabouraud broth supplemented with bacteriological agar (0.15 g/100 mL; dos Santos et al., 2012).

For the application of $\mathrm{CHI}$ and CAR in different combinations, CHI ( 7.5 or $3.75 \mathrm{mg} / \mathrm{mL}$ ) was diluted in acetic acid $(1 \mathrm{~mL} / 100 \mathrm{~mL})$ for $6 \mathrm{~h}$ at $\mathrm{RT}$ under stirring $(120 \mathrm{rpm})$. Then, different CAR concentrations $(5.0,2.5$, or $1.25 \mu \mathrm{L} / \mathrm{mL})$ were added and maintained under stirring (120 rpm) for an additional $18 \mathrm{~h}$ at RT (dos Santos et al., 2012). To assay the application of the dispersions containing $\mathrm{CHI}$ and $\mathrm{CAR}$ in combinations as coatings on tomato fruits, glycerol $(2 \mathrm{~mL} / 100 \mathrm{~mL})$ was incorporated (simultaneously to the CAR incorporation) as a plasticizer into the coating-forming dispersions (dos Santos et al., 2012).

\section{Determination of the Minimum Inhibitory Concentration}

The MIC of CHI and CAR was determined using broth macrodilution. For this, $1 \mathrm{~mL}$ of the fungal spore suspension was inoculated into $4 \mathrm{~mL}$ of Sabouraud broth (with the concentration adjusted to $10 \mathrm{~mL}$ ), and $5 \mathrm{~mL}$ of the solutions containing different CHI or CAR concentrations was added (dos Santos et al., 2012; de Sousa et al., 2013). The system was incubated at $28^{\circ} \mathrm{C}$ for a 7 days period. The lowest CHI or CAR concentration that displayed no visible fungal growth at the end of the incubation period was determined as the MIC (dos Santos et al., 2012).

\section{Effects on Mycelial Fungal Growth}

Inhibition of mycelial growth induced by $\mathrm{CHI}$ and CAR was determined using the agar dilution technique. Initially, $10 \mathrm{~mL}$ of the A. flavus spore suspension $\left(\sim 10^{6}\right.$ spores $\left./ \mathrm{mL}\right)$ was dispensed into $90 \mathrm{~mL}$ of Sabouraud broth (Himedia, India) containing different concentrations of $\mathrm{CHI}$ and CAR, followed for incubation at $25-28^{\circ} \mathrm{C}$. After 3 - and 7-days incubation period, the mycelial mass was obtained, dried at $60^{\circ} \mathrm{C}$ for $6 \mathrm{~h}$, and maintained at $40^{\circ} \mathrm{C}$ for $18 \mathrm{~h}$ (de Oliveira et al., 2014a,b). As a control assay, the target fungal suspension was inoculated in Sabouraud broth not containing CHI or CAR. For obtaining the percent inhibition of fungal mycelial growth, the comparison of the weights of the dry mycelial masses obtained from the suspensions exposed to CHI and CAR and from control assay at each of the assessed incubation periods was performed (de Sousa et al., 2013).

\section{Effects on Fungal Spore Germination}

The induction of inhibition in fungal spore germination by $\mathrm{CHI}$ and CAR was determined using a broth macrodilution technique. For this, aliquots $(0.1 \mathrm{~mL})$ of solutions containing different concentrations of $\mathrm{CHI}$ and CAR were mixed with $0.1 \mathrm{~mL}$ of the spore suspension $\left(\sim 10^{6}\right.$ spores $\left./ \mathrm{mL}\right)$ taken from a fungal culture cultivated for 10 days on Sabouraud agar (Himedia, India) at 25$28^{\circ} \mathrm{C}$. Afterward, $0.1 \mathrm{~mL}$ of the obtained suspension was placed at the center of a sterile glass slide, followed for incubation at $28^{\circ} \mathrm{C}$ for $24 \mathrm{~h}$ in a moisture chamber. After this period, the slides were fixed with lactophenol cotton blue stain, and the spore germination was observed using light microscopy (dos Santos et al., 2012). Approximately 200 spores were counted on each slide. In the control experiment, CHI and CAR solutions were replaced by Sabouraud broth. The percent inhibition of spore germination was obtained by comparing the number of germinated spores in the media containing CHI and CAR with the number of germinated spores obtained in the control assay (de Oliveira et al., 2014a,b). A spore was considered germinated when developed a germ tube presenting at least twice its original diameter. The results were expressed as percent inhibition rates of spore germination in comparison with the control assay (Aloui et al., 2014).

\section{Effects On A. flavus Infection in Fruits}

Cherry tomato fruits were first wounded $(3 \mathrm{~mm}$ deep and $3 \mathrm{~mm}$ wide; four wounds by each fruit; because A. flavus invades and causes rot in tomato fruits via wounds in skin of fruits - Snowdon, 1991) with a sterile needle in opposite sides. Thereafter, the fruits were inoculated by immersion in $500 \mathrm{~mL}$ of an inoculum solution $\left(\sim 10^{6}\right.$ spores $\left./ \mathrm{mL}\right)$ of $A$. flavus and sootrotated for 1 min using a sterile glass stem, and left to air-dry for $30 \mathrm{~min}\left(25^{\circ} \mathrm{C}\right)$. Then, the fruits were randomly distributed in different groups and immersed in $500 \mathrm{~mL}$ of the tested coating solutions with different $\mathrm{CHI}$ and CAR concentrations 
with slightly shaking for $1 \mathrm{~min}$ using a sterile glass stem. The fruits were allowed to air-dry and drain the excess liquid on a nylon-filter and packed in a commercially sterile polyethylene container (with a lid). One group of fruits was maintained at RT $\left[25^{\circ} \mathrm{C}\right.$, relative humidity $(\mathrm{RH})$ of $\left.85 \%\right]$, whereas the other was maintained at a low temperature $\left(\mathrm{LT} ; 12^{\circ} \mathrm{C}, \mathrm{RH}\right.$ of $85 \%$; de Oliveira et al., 2014a,b). Fruits submitted to LT storage were maintained at $12^{\circ} \mathrm{C}$ because tomato fruits are chilling sensitive at temperatures below $12^{\circ} \mathrm{C}$ (Tao et al., 2014). As a control treatment, sterile distilled water containing glycerol $(2 \mathrm{~g} / 100 \mathrm{~mL})$ were used in replacement of the $\mathrm{CHI}$ and CAR dispersions (dos Santos et al., 2012). Each treatment included 40 fruits, which were stored for different intervals (RT for 1, 4, 8, and 12 days; LT for $1,6,12$, and 24 days). The results were expressed as the storage time for appearance of visible signs of $A$. flavus infection and as the percentage of fruits that presented visible signs of $A$. flavus infection at different time intervals (dos Santos et al., 2012; de Oliveira et al., 2014a,b).

\section{Effects on Fungal Infection Caused by Native Fungal Microbiota}

Cherry tomato fruits (not surface disinfected) were immersed for one min in the solutions containing the CHI and CAR in different concentrations and soft-rotated for $1 \mathrm{~min}$ using a sterile glass stem, left to air-dry on a nylon-filter for $30 \mathrm{~min}\left(25^{\circ} \mathrm{C}\right)$ to drain the excess liquid and packed in a commercially sterile polyethylene container (with a lid). Thereafter, one group of fruits was stored at RT $\left(25^{\circ} \mathrm{C}\right.$, RH of $\left.85 \%\right)$ while the other group was stored at a $\mathrm{LT}\left(12{ }^{\circ} \mathrm{C}, \mathrm{RH}\right.$ of $85 \%$; de Sousa et al., 2013). As a control treatment, sterile distilled water containing glycerol $(2 \mathrm{~g} / 100 \mathrm{~mL})$ were used in replacement of the CHI and CAR dispersions (dos Santos et al., 2012). Each treatment included 40 fruits and different storage times (RT: 1, 4, 8, and 12 days; LT: $1,6,12,18$, and 24 days). The results were expressed as the storage time for appearance of visible signs of fungal infection and as percentage of fruits that presented visible signs of fungal infection at different storage time intervals times (dos Santos et al., 2012).

\section{Effects on Physicochemical Parameters of Fruits}

Cherry tomato fruits coated and uncoated with the different combinations of CHI and CAR were evaluated for weight loss, color, firmness, soluble solids (SSs) and titratable acidity (TA) at time $1,4,8$, and 12 days of storage at RT and at 1, 6, 12, and 24 days of storage at LT (five fruits were analyzed in each time interval). The SS content was determined using a digital refractometer (Model HI 96801, Hanna Instruments, São Paulo, Brazil), and the results were expressed as Brix (dos Santos et al., 2012). The TA was determined using phenolphthalein as an indicator with $0.1 \mathrm{~N} \mathrm{NaOH}$, and the results were expressed as mmol H$H^{+} / 100 \mathrm{~g}$ of fruit (dos Santos et al., 2012). The weight loss of fruits was measured by monitoring the weight of the fruit at different storage periods, and determined as a percentage of the initial weight (dos Santos et al., 2012). The skin color was determined at three different equatorial positions of the fruit using the CIEL $a b$ system $\left(\mathrm{L}^{*} \mathrm{a}^{*} \mathrm{~b}^{*}\right)$. Hue angle $\left(h^{*}{ }_{a b}\right)$ and chroma
$\left(C^{*}{ }_{a b}\right)$ were determined using a CR-300 colorimeter (MINOLTA Co., Osaka, Japan) and a 10-mm quartz cuvette for the readings, as described by the International Commission on Illumination (Commission Internationale de l'Éclairage [CIE], 1986; de Sousa et al., 2013). The CIELab color scale ( $\left.\mathrm{L}^{*} \mathrm{a}^{*} \mathrm{~b}^{*}\right)$ was used with a $\mathrm{D}^{65}$ illuminant (standard daylight) at a $10^{\circ}$ angle, and the apparatus was calibrated (using reference plates) in the reflectance mode (with specular reflection excluded). The firmness was determined using a 3-mm diameter probe (1/8) coupled to a TA-XT2 Texture Analyzer (Stable Micro Systems, Haslemere, UK), and the results were expressed as N/mm (de Sousa et al., 2013).

\section{Statistical Analysis}

The assessment of the effects on fungal growth/survival and on the physicochemical parameters of cherry tomato fruits was performed in triplicate in three different independent experiments, and the results were expressed as the mean of the data. Descriptive statistics (mean and SD) and inferential tests (ANOVA followed by the Mann-Whitney test or the Kruskal-Wallis test) were performed to determine statistically significant differences $(P \leq 0.05)$ between the treatments (coated and uncoated fruits). For statistical analysis, the computational software ORIGIN 8.0 (de Sousa et al., 2013) was used. For MIC determination assays, the results are expressed as modal values because the MIC values were the same in all repetitions.

\section{Results}

\section{In Vitro Anti-A. Flavus Effects}

Chitosan and CAR displayed MIC values of $7.5 \mathrm{mg} / \mathrm{mL}$ and $10 \mu \mathrm{L} / \mathrm{mL}$, respectively, against $A$. flavus. CHI at 7.5 or $3.75 \mathrm{mg} / \mathrm{mL}$ and $\mathrm{CAR}$ at 5 and $2.5 \mu \mathrm{L} / \mathrm{mL}$ were tested in different combinations (CHI $7.5 \mathrm{mg} / \mathrm{mL}+$ CAR $5 \mu \mathrm{L} / \mathrm{mL}$, CHI $7.5 \mathrm{mg} / \mathrm{mL}+$ CAR $2.5 \mu \mathrm{L} / \mathrm{mL}, \mathrm{CHI} 3.75 \mathrm{mg} / \mathrm{mL}+\mathrm{CAR}$ $5 \mu \mathrm{L} / \mathrm{mL}$ and CHI $3.75 \mathrm{mg} / \mathrm{mL}+$ CAR $2.5 \mu \mathrm{L} / \mathrm{mL}$ ) in assays that measured the effects on mycelial growth and spore germination of A. flavus. During the 7-days incubation-period, the combined $\mathrm{CHI}$ and CAR concentrations strongly inhibited the mycelial growth of A. flavus (77.2-100\%) when compared with the control assay (Table 1). The application of CHI and CAR at the different tested combinations also showed high rates of spore germination inhibition on A. flavus (86.3-100\%; Table 1). The rates of spore germination inhibition caused by all assayed combined concentrations were as higher as $85 \%$ when compared with the number of spores germinated in the control treatment (germinated spores number near to $8.3 \times 10^{5}$ spores $/ \mathrm{mL}$ ). The combination of CHI $7.5 \mathrm{mg} / \mathrm{mL}+$ CAR $5 \mu \mathrm{L} / \mathrm{mL}$ presented the highest rates $(P \leq 0.05)$ of inhibition on $A$. flavus in either the mycelial growth or spore germination assay.

Given the strong inhibition of mycelial growth and fungal spore germination, $\mathrm{CHI}$ and CAR were assayed in combinations of CHI $3.75 \mathrm{mg} / \mathrm{mL}+$ CAR $2.5 \mu \mathrm{L} / \mathrm{mL}$ and CHI $3.75 \mathrm{mg} / \mathrm{mL}+$ CAR $1.25 \mu \mathrm{L} / \mathrm{mL}$ to evaluate the effects as a coating on the development of A. flavus infection on cherry tomato fruits, as well as the effects on physicochemical quality parameters of the fruits during storage. 
TABLE 1 | Inhibition percentage of fungal mycelial growth and spore germination of Aspergillus flavus URM 4550 in liquid medium containing chitosan (CHI) from Mucor circinelloides UCP 050 (CHI) and carvacrol (CAR) at different concentrations.

\begin{tabular}{|c|c|c|c|}
\hline \multirow[t]{3}{*}{ Treatment } & \multicolumn{2}{|c|}{ Mycelial growth inhibition } & \multirow[t]{3}{*}{ Spore germination inhibition } \\
\hline & \multicolumn{2}{|c|}{ Exposure time } & \\
\hline & 3 days & 7 days & \\
\hline $\mathrm{CHI} 7.5 \mathrm{mg} / \mathrm{mL}+\mathrm{CAR} 5 \mu \mathrm{L} / \mathrm{mL}$ & $88.3 \%( \pm 0.0 \%)^{\mathrm{Aa}}$ & $100 \%( \pm 0.0 \%)^{A b}$ & $100 \%( \pm 0.0 \%)^{\mathrm{A}}$ \\
\hline $\mathrm{CH} 7.5 \mathrm{mg} / \mathrm{mL}+\mathrm{CAR} 2.5 \mu \mathrm{L} / \mathrm{mL}$ & $79.4 \%( \pm 4.1 \%)^{\mathrm{Ba}}$ & $95.3 \%( \pm 1.5 \%)^{\mathrm{Bb}}$ & $94.1 \%( \pm 1.30 \%)^{\mathrm{B}}$ \\
\hline $\mathrm{CHI3.75} \mathrm{mg/mL} \mathrm{+} \mathrm{CAR5} \mu \mathrm{L} / \mathrm{mL}$ & $78.1 \%( \pm 3.9 \%)^{\mathrm{Ba}}$ & $92.3 \%( \pm 2.9 \%)^{\mathrm{Bb}}$ & $88.4 \%( \pm 3.6 \%)^{\mathrm{B}}$ \\
\hline $\mathrm{CHI} 3.75 \mathrm{mg} / \mathrm{mL}+\mathrm{CAR} 2.5 \mu \mathrm{L} / \mathrm{mL}$ & $77.2 \%( \pm 2.3 \%)^{\mathrm{Ba}}$ & $88.2 \%( \pm 3.1 \%)^{\mathrm{Bb}}$ & $86.3 \%( \pm 2.5 \%)^{\mathrm{B}}$ \\
\hline
\end{tabular}

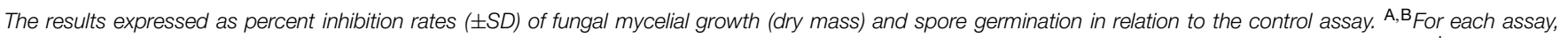

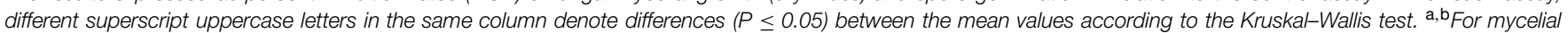

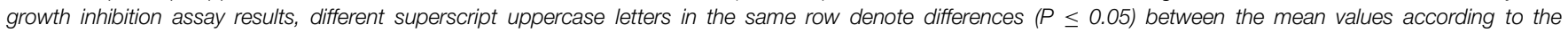
Mann-Whitney test.

\section{In Situ Antifungal Effects}

When fresh cherry tomato fruits were artificially contaminated with spores of A. flavus and treated with the coatings composed of $\mathrm{CHI}$ and CAR combined at different combinations, the A. flavus growth was delayed during the storage at both RT and LT (Table 2). The tomato fruits stored at RT and coated with $\mathrm{CHI}$ $3.75 \mathrm{mg} / \mathrm{mL}+$ CAR $2.5 \mu \mathrm{L} / \mathrm{mL}$ displayed visible signs (signs) of A. flavus infection only at the last assessed storage time interval (12th day, $15 \%$ of fruits were infected). Fruits coated with CHI $3.75 \mathrm{mg} / \mathrm{mL}+$ CAR $1.25 \mu \mathrm{L} / \mathrm{mL}$ and stored at RT revealed signs of infection on the eighth day of storage (25\% of fruits were infected), and $30 \%$ of the fruits were infected at the end of the assessed storage period (12th day). Fruits uncoated with CHI and CAR exhibited signs of infection as early as the fourth day of storage at RT (65\% of fruits were infected), and all of these fruits displayed infection signs at the end of the storage period (Table 2).

Fruits coated with CHI $3.75 \mathrm{mg} / \mathrm{mL}$ + CAR $1.25 \mu \mathrm{L} / \mathrm{mL}$ displayed signs of infection only from the 12th day of storage at LT ( $15 \%$ of fruits were infected), but only $20 \%$ of the fruits were infected at the end of the assessed storage period (24th day). Fruits that were not coated with CHI and CAR and were stored at LT exhibited signs of $A$. flavus infection at the sixth day of storage ( $70 \%$ of fruits were infected), and at the end of the assessed storage period $93 \%$ of these fruits were infected (Table 2). In general, the inhibition of $A$. flavus infection in cherry tomato fruits by the combinations of $\mathrm{CHI}$ and CAR was weakened over time.

The application of the coatings composed of $\mathrm{CHI}$ and CAR also inhibited the occurrence of infection caused by native fungal population in cherry tomato fruits (Table 3). Fungal infection was not visible in fruits treated with the coating containing $\mathrm{CHI}$ $3.75 \mathrm{mg} / \mathrm{mL}+$ CAR $2.5 \mu \mathrm{L} / \mathrm{mL}$ or CHI $3.75 \mathrm{mg} / \mathrm{mL}+$ CAR $1.25 \mu \mathrm{L} / \mathrm{mL}$ during the assessed storage intervals at LT. The fruits treated with coating containing CHI $3.75 \mathrm{mg} / \mathrm{mL}+$ CAR $1.25 \mu \mathrm{L} / \mathrm{mL}$ displayed signs of fungal infection from the fourth day of storage at RT (15\% of fruits were infected), and $25 \%$ of these fruits were infected at the end of the assessed storage period. Fruits treated with the coating containing $\mathrm{CHI}$ $3.75 \mathrm{mg} / \mathrm{mL}+\mathrm{CAR} 2.5 \mu \mathrm{L} / \mathrm{mL}$ and stored at RT only displayed

TABLE 2 | Mean values for incidence of $A$. flavus infection on cherry tomato fruits uncoated and coated with the combination of chitosan from M. circinelloides UCP 050 (CHI) and carvacrol (CAR) at different concentrations and stored at room temperature (RT; $25^{\circ} \mathrm{C}$ ) for 12 days or at low temperature $\left(\mathrm{LT} ; \mathbf{1 2}^{\circ} \mathrm{C}\right)$ for 24 days.

\begin{tabular}{|c|c|c|c|c|}
\hline Treatment & \multicolumn{4}{|c|}{ Days of storage (RT) } \\
\hline Control* & $0 \%( \pm 0 \%)^{\mathrm{a}}$ & $65 \%( \pm 3 \%)^{b}$ & $83 \%( \pm 4 \%)^{c}$ & $100 \%( \pm 0 \%)^{d}$ \\
\hline $\mathrm{CHI} 3.75 \mathrm{mg} / \mathrm{mL}+\mathrm{CAR} 2.5 \mu \mathrm{L} / \mathrm{mL}$ & $0 \%( \pm 0 \%)^{a}$ & $0 \%( \pm 0 \%)^{\mathrm{a}}$ & $0 \%( \pm 0 \%)^{a}$ & $15 \%( \pm 1 \%)^{b}$ \\
\hline $\mathrm{CHI} 3.75 \mathrm{mg} / \mathrm{mL}+$ CAR $1.25 \mu \mathrm{L} / \mathrm{mL}$ & $0 \%( \pm 0 \%)^{a}$ & $0 \%( \pm 0 \%)^{a}$ & $25 \%( \pm 2 \%)^{b}$ & $30 \%( \pm 3 \%)^{b}$ \\
\hline Treatment & 1 & 6 & 12 & 24 \\
\hline Control* & $0 \%( \pm 0 \%)$ & $70 \%( \pm 2 \%)^{b}$ & $78 \%( \pm 3 \%)^{\mathrm{c}}$ & $93 \%( \pm 2 \%)^{c}$ \\
\hline $\mathrm{CHI} 3.75 \mathrm{mg} / \mathrm{mL}+\mathrm{CAR} 2.5 \mu \mathrm{L} / \mathrm{mL}$ & $0 \%( \pm 0 \%)$ & $0 \%( \pm 0 \%)^{\mathrm{a}}$ & $0 \%( \pm 0 \%)^{a}$ & $0 \%( \pm 0 \%)^{\mathrm{a}}$ \\
\hline $\mathrm{CHI} 3.75 \mathrm{mg} / \mathrm{mL}+$ CAR $1.25 \mu \mathrm{L} / \mathrm{mL}$ & $0 \%( \pm 0 \%)$ & $0 \%( \pm 0 \%)^{a}$ & $15 \%( \pm 1 \%)^{b}$ & $20 \%( \pm 1 \%)^{b}$ \\
\hline
\end{tabular}

*Control: $\mathrm{CHI} 0 \mathrm{mg} / \mathrm{mL}+\mathrm{CAR} 0 \mu \mathrm{L} / \mathrm{mL}$. a-d For each trial, different superscript lowercase letters in the column denote differences $(P \leq 0.05)$ between the mean values according to Kruskal-Wallis test. 
TABLE 3 | Mean values for incidence of visible signs of fungal infection (caused by native fungal microbiota) on cherry tomato fruits uncoated and coated with the combination of chitosan from $M$. circinelloides UCP 050 (CHI) and carvacrol (CAR) at different concentrations, and stored at room temperature $\left(\mathrm{RT} ; 2^{\circ} \mathrm{C}\right.$ ) for 12 days or at low temperature (LT; $12^{\circ} \mathrm{C}$ ) for 24 days.

\begin{tabular}{|c|c|c|c|c|}
\hline \multirow[t]{2}{*}{ Treatment } & \multicolumn{4}{|c|}{ Days of storage (RT) } \\
\hline & 1 & 4 & 8 & 12 \\
\hline Control* & $0 \%( \pm 0 \%)$ & $65 \%( \pm 2 \%)^{b}$ & $73 \%( \pm 2 \%)^{c}$ & $100 \%( \pm 0 \%)^{c}$ \\
\hline $\mathrm{CHI} 3.75 \mathrm{mg} / \mathrm{mL}+\mathrm{CAR} 2.5 \mu \mathrm{L} / \mathrm{mL}$ & $0 \%( \pm 0 \%)$ & $0 \%( \pm 0 \%)^{a}$ & $0 \%( \pm 0 \%)^{a}$ & $10 \%(1 \%)^{a}$ \\
\hline $\mathrm{CHI} 3.75 \mathrm{mg} / \mathrm{mL}+\mathrm{CAR} 1.25 \mu \mathrm{L} / \mathrm{mL}$ & $0 \%( \pm 0 \%)$ & $15 \%( \pm 1 \%)^{b}$ & $20 \%( \pm 2 \%)^{b}$ & $25 \%( \pm 1 \%)^{\mathrm{b}}$ \\
\hline \multirow[t]{2}{*}{ Treatment } & \multicolumn{4}{|c|}{ Days of storage (LT) } \\
\hline & 1 & 6 & 12 & 24 \\
\hline Control* & $0 \%( \pm 0 \%)$ & $0 \%( \pm 0 \%)$ & $62 \%( \pm 3 \%)^{b}$ & $86 \%( \pm 2 \%)^{b}$ \\
\hline $\mathrm{CHI} 3.75$ mg/mL + CAR $2.5 \mu \mathrm{L} / \mathrm{mL}$ & $0 \%( \pm 0 \%)$ & $0 \%( \pm 0 \%)$ & $0 \%( \pm 0 \%)^{a}$ & $0 \%( \pm 0 \%)^{\mathrm{a}}$ \\
\hline $\mathrm{CHI} 3.75 \mathrm{mg} / \mathrm{mL}+\mathrm{CAR} 1.25 \mu \mathrm{L} / \mathrm{mL}$ & $0 \%( \pm 0 \%)$ & $0 \%( \pm 0 \%)$ & $0 \%( \pm 0 \%)^{a}$ & $0 \%( \pm 0 \%)^{a}$ \\
\hline
\end{tabular}

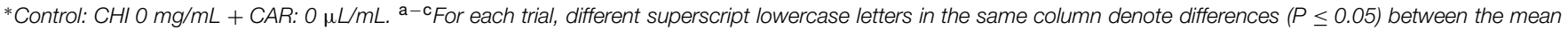
values according to Kruskal-Wallis test.

signs of fungal infection (10\% of fruits were infected) at the last assessed storage interval (12th day). Cherry tomato fruits not treated with the coatings containing $\mathrm{CHI}$ and CAR showed signs of fungal infection at the 4 th $(65 \%$ of fruits were infected) and 12 th (62\% of fruits were infected) days when stored at RT and LT, respectively. In general, the antifungal effects of the coatings containing $\mathrm{CHI}$ and CAR occurred in a dosagedependent manner in both in vitro and in situ assays.

\section{Effects On Physicochemical Characteristics of Fruits}

Some physicochemical parameters in fresh cherry tomato fruits uncoated or coated with CHI3.75 mg/mL + CAR $2.5 \mu \mathrm{L} / \mathrm{mL}$ or CHI $3.75 \mathrm{mg} / \mathrm{mL}+\mathrm{CAR} 1.25 \mu \mathrm{L} / \mathrm{mL}$ were evaluated during storage (Table 4). For most of them, no differences $(P>0.05)$ were observed among the coated and non-coated fruits during the assessed storage periods at both RT and LT.

Fruits coated or uncoated with the combinations of $\mathrm{CHI}$ and CAR differed $(P \leq 0.05)$ in weight loss at the end of the storage time, although the weight loss of all fruits groups increased gradually during storage. Fruits coated with $\mathrm{CHI}$ $3.75 \mathrm{mg} / \mathrm{mL}+$ CAR $2.5 \mu \mathrm{L} / \mathrm{mL}$ or CHI $3.75 \mathrm{mg} / \mathrm{mL}+$ CAR $1.25 \mu \mathrm{L} / \mathrm{mL}$ and stored at RT exhibited weight losses of 14.2 and $11.1 \%$, respectively, at the end of the assessed storage time interval. The weight losses of the tomato fruits coated with either the combination of CHI $3.75 \mathrm{mg} / \mathrm{mL}+\mathrm{CAR} 2.5 \mu \mathrm{L} / \mathrm{mL}$ or $\mathrm{CHI}$ $3.75 \mathrm{mg} / \mathrm{mL}+\mathrm{CAR} 1.25 \mu \mathrm{L} / \mathrm{mL}$ and stored at LT were 7.1 and $10.1 \%$, respectively, at the end of the assessed storage period. The uncoated fruits stored at RT and LT displayed weight loss of 25.2 and $21.3 \%$ at the end of the assessed storage period.

No difference $(P>0.05)$ in firmness was observed among coated and uncoated fruits during the storage at LT. Both the coated and uncoated fruits presented a sharp decrease $(P \leq 0.05)$ in firmness during the storage period at both tested storage temperatures. Otherwise, cherry tomato fruits coated with the combinations of $\mathrm{CHI}$ and CAR presented higher $(P \leq 0.05)$ values of TA than the uncoated fruits when stored at RT.
Moreover, uncoated fruits displayed higher $(P \leq 0.05)$ values of SS than the coated fruits from the 4 th day of storage at RT onward. Cherry tomato fruits coated or uncoated with combinations of CHI and CAR and stored at LT did not differ $(P>0.05)$ in any of the studied physicochemical parameters at all assessed time intervals, with exception of weight loss from the sixth day of storage onward.

The cherry tomato fruits uncoated and coated with $\mathrm{CHI}$ $3.75 \mathrm{mg} / \mathrm{mL}+$ CAR $2.5 \mathrm{~L} / \mathrm{mL}$ or CHI $3.75 \mathrm{mg} / \mathrm{mL}+$ CAR $1.25 \mu \mathrm{L} / \mathrm{mL}$ were predominantly red throughout storage at both tested storage temperatures. The fruits submitted to all treatment conditions displayed an increase $(P \leq 0.05)$ in $a^{*}$ and $b^{*}$ coordinates, resulting in a lightness decrease because of the enhancement in fruit opacity. For coated and uncoated fruits, there was a decrease $(P \leq 0.05)$ in $h^{*}$ values and maintenance $(P>0.05)$ of $C^{*}$ values during storage, showing a color change from red to dark red. Still, both coated and uncoated fruits also displayed similar $(P>0.05) \mathrm{L}^{*}$ values during storage, showing the maintenance of brightness (data not shown).

Taken together, these results demonstrate that combinations of $\mathrm{CHI}$ and CAR at subinhibitory concentrations effectively reduce fungal decay and maintain the quality of fresh cherry tomato fruits over storage.

\section{Discussion}

The combined application of $\mathrm{CHI}$ and CAR at different concentrations (MIC values and/or subinhibitory concentrations) induced the inhibition of the mycelial growth and spore germination of $A$. flavus in laboratory media. These findings are interesting because fungi are commonly less tolerant to antimicrobial compounds during the mycelial growth stages than during the spore germination stage, most likely because the stronger antimicrobial resistance of fungal spore structures (de Oliveira et al., 2014a,b). The strong and fast inhibition of A. flavus spore germination induced by $\mathrm{CHI}$ and CAR is worthy of note considering their practical application on fruits because 
TABLE 4 | Mean values for weight loss and some physicochemical quality parameters in cherry tomato fruits uncoated and coated with the combination of $\mathrm{CHI}$ from $\mathrm{M}$. circinelloides UCP 050 (CHI) and carvacrol (CAR) at different concentrations and stored at room temperature (RT; $25^{\circ} \mathrm{C}$ ) for 12 days or at low temperature (LT; $\left.12^{\circ} \mathrm{C}\right)$ for 24 days.

Treatment

Days of storage (RT)

\begin{tabular}{llll}
\hline 1 & 4 & 8 & 12
\end{tabular}

\section{Weight loss $(\%)$}

Control*

$\mathrm{CH} 3.75 \mathrm{mg} / \mathrm{mL}+\mathrm{CAR} 2.5 \mu \mathrm{L} / \mathrm{mL}$

$3.1 \%( \pm 0.3)^{\mathrm{b}}$

$0.0 \%( \pm 0.0)^{\mathrm{a}}$

$21.4 \%( \pm 2.7)^{\mathrm{b}}$

$12.1 \%( \pm 1.8)^{\mathrm{a}}$

$25.2 \%( \pm 2.7)^{\mathrm{b}}$

$10.3 \%( \pm 1.5)^{\mathrm{c}}$
$6.5 \%( \pm 1.2)^{\mathrm{b}}$
$4.3 \%( \pm 0.9)^{\mathrm{a}}$

$14.1 \%( \pm 1.9)^{\mathrm{a}}$

$\mathrm{CHI} 3.75 \mathrm{mg} / \mathrm{mL}+\mathrm{CAR} 1.25 \mu \mathrm{L} / \mathrm{mL}$

$0.0 \%( \pm 0.0)^{a}$

$10.1 \%( \pm 1.3)^{\mathrm{a}}$

Firmness (N/mm)

Control

$4.9( \pm 0.8)$

$(3.30 .8)$

CHI $3.75 \mathrm{mg} / \mathrm{mL}+$ CAR $2.5 \mu \mathrm{L} / \mathrm{mL}$

$5.1( \pm 0.9)$

$3.3( \pm 0.8)$

$5.1( \pm 0.9)$

$4.6( \pm 0.9)$

$3.7( \pm 0.9)$

$3.6( \pm 0.5)$

$3.9( \pm 0.9)$

$3.6( \pm 0.8)$

$11.1 \%( \pm 1.1)^{\mathrm{a}}$

Titratable acidity $\left(\mathrm{mmol} \mathrm{H}^{+} / 100 \mathrm{~g}\right.$ of fruit)

\section{Control*}

$\mathrm{CHI} 3.75 \mathrm{mg} / \mathrm{mL}+\mathrm{CAR} 2.5 \mu \mathrm{L} / \mathrm{mL}$

$\mathrm{CHI} 3.75 \mathrm{mg} / \mathrm{mL}+\mathrm{CAR} 1.25 \mu \mathrm{L} / \mathrm{mL}$

$\begin{array}{ll}0.4( \pm 0.1)^{\mathrm{a}} & 0.32( \pm 0.0)^{\mathrm{a}} \\ 0.4( \pm 0.1)^{\mathrm{b}} & 0.40( \pm 0.0)^{\mathrm{b}} \\ 0.4( \pm 0.2)^{\mathrm{b}} & 0.40( \pm 0.0)^{\mathrm{b}}\end{array}$

$0.2( \pm 0.1)^{\mathrm{a}}$

$0.3( \pm 0.0)^{b}$

$0.3( \pm 0.0)^{\mathrm{b}}$

$3.5( \pm 0.74)$

$3.9( \pm 0.75)$

$3.4( \pm 0.78)$

\section{Soluble solids ( ${ }^{\circ}$ Brix)}

Control*

$\mathrm{CHI} 3.75 \mathrm{mg} / \mathrm{mL}+\mathrm{CAR} 2.5 \mu \mathrm{L} / \mathrm{mL}$

$\mathrm{CH} 3.75 \mathrm{mg} / \mathrm{mL}+\mathrm{CAR} 1.25 \mu \mathrm{L} / \mathrm{mL}$
$5.0( \pm 0.3)^{\mathrm{b}}$
$4.0( \pm 0.2)^{\mathrm{a}}$
$3.8( \pm 0.4)^{\mathrm{a}}$

\section{$5.2( \pm 0.3)^{b}$ \\ $4.2( \pm 0.2)^{a}$ \\ $4.2( \pm 0.3)^{a}$}

$0.20( \pm 0.0)^{\mathrm{a}}$

$0.30( \pm 0.0)^{\mathrm{b}}$

$0.29( \pm 0.1)^{b}$
$5.36( \pm 0.4)^{b}$

$4.43( \pm 0.3)^{\mathrm{a}}$

$4.52( \pm 0.7)^{\mathrm{a}}$

Treatment

Days of Storage (LT)

\begin{tabular}{llll}
\hline 1 & 6 & 12 & 24
\end{tabular}

\section{Weight loss (\%)}

Control*

$\mathrm{CH} 3.75 \mathrm{mg} / \mathrm{mL}+\mathrm{CAR} 2.5 \mu \mathrm{L} / \mathrm{mL}$

$0.0 \%( \pm 0.0) \quad 6.4 \%( \pm 1.2)^{\mathrm{c}}$

$0.0 \%( \pm 0.0) \quad 2.1 \%( \pm 0.4)^{\mathrm{b}}$

$15.0 \%( \pm 1.6)^{\mathrm{b}}$

$5.1 \%( \pm 0.4)^{\mathrm{a}}$

$3.4 \%( \pm 0.4)^{\mathrm{a}}$

$6.1 \%( \pm 0.5)^{\mathrm{a}}$

$\mathrm{CH} 3.75 \mathrm{mg} / \mathrm{mL}+\mathrm{CAR} 1.25 \mu \mathrm{L} / \mathrm{mL}$

$0.0 \%( \pm 0.0)$

$4.6( \pm 0.3)$

$5.3( \pm 0.5) \quad 4.6( \pm 0.3)$

$5.4( \pm 0.4) \quad 4.7( \pm 0.8)$

$4.1( \pm 0.6)$

$4.1( \pm 0.5)$

$4.9( \pm 0.8)$

$4.2( \pm 0.7)$

$5.8( \pm 0.3)$

$0.4( \pm 0.0)$

$0.4( \pm 0.0)$

$0.3( \pm 0.0)$

$0.3( \pm 0.1)$

$0.4( \pm 0.1)$

$21.3 \%( \pm 2.2)^{\mathrm{c}}$

$7.1 \%( \pm 0.6)^{\mathrm{b}}$

$10.1 \%( \pm 1.5)^{\mathrm{a}}$

$\begin{array}{llll}0.5( \pm 0.0) & 0.4( \pm 0.0) & 0.3( \pm 0.0) & 0.3( \pm 0.1) \\ 0.5( \pm 0.4) & 0.4( \pm 0.0) & 0.3( \pm 0.1) & 0.3( \pm 0.0) \\ 0.4( \pm 0.6) & 0.4( \pm 0.1) & 0.4( \pm 0.1) & 0.3( \pm 0.0)\end{array}$

$\mathrm{CH} 3.75 \mathrm{mg} / \mathrm{mL}+\mathrm{CAR} 1.25 \mu \mathrm{L} / \mathrm{mL}$

$4.0( \pm 0.8)$

$4.8( \pm 0.3)$

$5.1( \pm 0.6)$

$4.3( \pm 0.2)$

$4.3( \pm 0.6)$

$4.8( \pm 0.6)$

$5.2( \pm 0.6)$

$4.4( \pm 0.2)$

$4.4( \pm 0.7)$

$4.9( \pm 0.5)$

$5.1( \pm 0.7)$

*Control: CHI $0 \mathrm{mg} / \mathrm{mL}+\mathrm{CAR}: 0 \mu \mathrm{L} / \mathrm{mL}$. ${ }^{\mathrm{a}-\mathrm{c}}$ For each trial, different superscript lowercase letters in the same column denote differences (P $\left.\leq 0.05\right)$ between the mean values according to Kruskal-Wallis test.

the spores are important structures in the survival and spread of pathogenic fungi in horticultural products, causing the fruits infections, rot development and postharvest losses (de Sousa et al., 2013).

The combinations of CHI and CAR also presented strong antifungal effects when it was applied forming different coatings on cherry tomato fruits artificially contaminated with A. flavus spores, as well as against the native mycoflora of these fruits during storage at RT or LT. The CHI concentrations of 7 and
$3.75 \mathrm{mg} / \mathrm{mL}$ were used to form the tested coatings because $3.75 \mathrm{mg} / \mathrm{mL}$ was the lowest CHI concentration that was capable of forming a viscous solution that permitted its application as a coating for grapes. Still, CHI at $10 \mathrm{mg} / \mathrm{mL}$ formed highly viscous dispersions that did permit the formation of continuous films when they were applied to fruits. For CAR, the concentrations were set at 5 and $2.5 \mu \mathrm{L} / \mathrm{mL}$ because researchers have stated that essential oils or their individual constituents could be incorporated at low concentrations $(<10 \mu \mathrm{L} / \mathrm{mL})$ in coating 
dispersions to minimize their possible impact on the olfactory perception of consumers (Perdones et al., 2012).

An early study found that the combination of crustacean $\mathrm{CHI}$ and Origanum vulagre L. essential oil (OVEO), presenting CAR as the major compound $(66.9 \mathrm{~g} / 100 \mathrm{~mL})$, at subinhibitory amounts caused high inhibition rates of spores germination and morphological changes in spores (wilting, disruption, loss of cellular material and deepening of ridges) of Aspergillus niger and Rhizopus stolonifer (dos Santos et al., 2012). The authors also detected decreased occurrence of infections caused by $A$. niger and $R$. stolonifer in artificially contaminated table grapes that were treated with the combinations of CHI and OVEO (dos Santos et al., 2012). The mechanism by which $\mathrm{CHI}$ and OVEO induce the inhibition of spore germination has been related with the interaction of $\mathrm{CHI}$ and the essential oil individual constituents, mainly the major compound CAR, with the spore cell wall. The negative effect of CAR on enzymatic reactions needed for the synthesis of fungal spore cell wall components is also related with its effects on spores germination and viability and ultimately the fungal growth (dos Santos et al., 2012; de Sousa et al., 2013).

The effects of the coating comprising the combinations of $\mathrm{CHI}$ and CAR in delaying the appearance of A. flavus infection in cherry tomato fruits increased when the fruits were stored at LT. Researchers have proposed that storage at LT slows physiological processes in fruits and delay the senescence, becoming the fruits more resistant to fungal diseases. Moreover, it has been proposed that most of the postharvest pathogen fungi have weaker pathogenicity at LT, resulting in a decreased incidence of fungal infections and decay compared to fruit stored at RT (de Oliveira et al., 2014a,b).

The application of the coatings containing $\mathrm{CHI}$ and CAR did not negatively affected the physicochemical characteristics of cherry tomato fruits throughout the storage period, as assessed by weight loss, firmness, TA value, and SS content. Tomato fruits coated with the combinations of CHI and CAR lost less weight during storage at either RT or LT. Weight loss in fresh fruits is primarily associated with the water loss caused by transpiration and respiration (Meng et al., 2008). Decreased weight loss in cherry tomato fruits coated with $\mathrm{CHI}$ and CAR is associated with the formation of a protective barrier that reduces respiration and transpiration across the fruit surface (Liu et al., 2007; Gol et al., 2013). Because of its hydrophobic properties, the incorporation of CAR into $\mathrm{CHI}$-based coatings may improve the preventive effects and reduce moisture loss in coated cherry tomato fruits (Vargas et al., 2008).

\section{References}

Ali, A., Muhammad, M. T. M., Sijam, K., and Siddiqui, Y. (2011). Effect of chitosan coatings on the physicochemical characteristics of Eksotika II papaya (Carica papaya L.) fruit during cold storage. Food Chem. 124, 620-626. doi: 10.1016/j.foodchem.2010.06.085

Aloui, H., Khwaldia, K., Licciardello, F., Mazzaglia, A., Muratore, G., Hamdi, M., et al. (2014). Efficacy of the combined application of chitosan and Locust
The coatings composed of $\mathrm{CHI}$ and CAR induced a decrease in the SS contents of cherry tomato fruits stored at RT. This decrease could be associated with the slowing of respiration and metabolic activity in the fruit, hence delaying the ripening process (Hong et al., 2012). CHI-based dispersions are capable of forming a semi-permeable barrier when applied as a coating in fruits, reducing $\mathrm{O}_{2}$ and/or elevating $\mathrm{CO}_{2}$ and suppressing ethylene production (Dong et al., 2004; de Oliveira et al., 2014a). This suppressed respiration rate slows down the metabolic activity, resulting in lower levels of SS because the slower hydrolysis of carbohydrates to sugars (Hong et al., 2012; Gol et al., 2013; de Oliveira et al., 2014a). Previous studies also found that the application of coatings composed of $\mathrm{CHI}$, alone or in combination with essential oil individual constituents, decreased the amount of SS in different fruits (Kitur et al., 2001; Ali et al., 2011; dos Santos et al., 2012; de Oliveira et al., 2014b), and these changes were most pronounced in RT-stored fruits.

Although the impact of the composite coatings containing $\mathrm{CHI}$ and CAR on sensory characteristics of cherry tomato fruits has not been assessed, previous studies found that the application of essential oils containing CAR as major constituent (>65/100 g) alone or combined with CHI do not impact negatively the sensory acceptance and purchase intention of fruits (dos Santos et al., 2012; de Sousa et al., 2013).

The results obtained in this study revealed that the application of coatings composed of CHI from M. circinelloides and CAR at different subinhibitory concentrations can significantly inhibit the postharvest pathogenic fungus A. flavus, as well as the native fungal microbiota, on fresh cherry tomato fruits during storage at RT and LT. However, these inhibitory effects were more pronounced when the fruits were stored at LT. Moreover, the tested coatings displayed no negative influence on the physicochemical aspects of cherry tomato fruits during the storage. These findings demonstrate the potential for using $\mathrm{CHI}$ from M. circinelloides and CAR for the formulation of coatings to be applied in the control of pathogenic fungi in fruits, particularly A. flavus on cherry tomato fruits, which may be non-chemical alternatives to improve the quality of these commodities and provide greater economic benefits to producers.

\section{Acknowledgments}

The authors are grateful to the National Council for Scientific and Technological Development (CNPq, Brazil) and the Ministry of Agricultural and Livestock (MAPA, Brazil) for the financial support (Grant 578072/2008-4).

Bean Gum with different citrus essential oils to control postharvest spoilage caused by Aspergillus flavus in dates. Int. J. Food Microbiol. 170, 21-28. doi: 10.1016/j.ijfoodmicro.2013.10.017

Badawy, M. E. I., and Rabea, E. I. (2009). Potential of the biopolymer chitosan with different molecular weights to control postharvest gray mold of tomato fruit. Postharvest Biol. Tec. 51, 110-117. doi: 10.1016/j.postharvbio.2008.05.018

Berger, L. R. R., Stamford, T. C. M., Stamford-Arnaud, T. M., Franco, L. O., Nascimento, A. E., Cavalcante, H. M. M., et al. (2014). Effect of corn steep 
liquor (CSL) and cassava wastewater (CW) on chitin and chitosan production by Cunninghamella elegans and their physicochemical characteristics and cytotoxicity. Molecules 19, 2771-2792. doi: 10.3390/molecules 19032771

Beyki, M., Zhaveh, S., Khalili, S. T., Rahmani-Cherati, T., Abollahi, A., Bayat, M., et al. (2014). Encapsulation of Mentha piperita essential oils in chitosancinnamic acid nanogel with enhanced antimicrobial activity against Aspergillus flavus. Ind. Crops Prod. 54, 310-319. doi: 10.1016/j.indcrop.2014.01.033

Burt, S. (2004). Essential oils: their antibacterial properties and potential applications in foods-a review. Int. J. Food Microbiol. 94, 223-253. doi: 10.1016/j.ijfoodmicro.2004.03.022

Chen, J., Zou, X., Liu, Q., Wang, F., Feng, W., and Wan, N. (2014). Combination effect of chitosan and methyl jasmonate on controlling Alternaria alternate and enhancing of cherry tomato fruits defense mechanisms. Crop Prot. 56, 31-36. doi: $10.1016 /$ j.cropro.2013.10.007

Commission Internationale de l'Éclairage [CIE]. (1986). Colourimetry, 2nd Edn. Vienna: CIE publication.

Coqueiro, D. S. O., Maraschin, M., and Di Piero, M. (2011). Chitosan reduces bacterial spot severity and acts in phenylpropanoid metabolism in tomato plants. J. Phytopahol. 159, 488-494. doi: 10.1111/j.1439-0434.2011.01791.x

de Oliveira, C. E., Magnani, M., Sales, C. V., Pontes, A. L. S., CamposTakaki, G. M., Stamford, T. C. M., et al. (2014a). Effects of chitosan from Cunninghamella elegans on virulence of postharvest pathogenic fungi in table grapes (Vitis Labrusca L.). Int. J. Food Microbiol. 171, 54-61.doi: 10.1016/j.ijfoodmicro.2013.11.006

de Oliveira, C. E., Magnani, M., Sales, C. V., Pontes, A. L. S., CamposTakaki, G. M., Stamford, T. C. M., et al. (2014b). Effects of postharvest treatment using chitosan from Mucor circinelloides on fungal pathogenicity and quality of table grapes during storage. Food Microbiol. 44, 211-219. doi: 10.1016/j.fm.2014.06.007

de Sousa, L. L., Andrade, S. C. A., Athayde, A. J. A. A., Oliveira, C. E. V., Sales, C. V., Madruga, M. S., et al. (2013). Efficacy of Origanum vulgare L. and Rosmarinus officinalis L. essential oils in combination to control postharvest pathogenic Aspergilli and autochthonous mycoflora in Vitris labrusca L. (table grapes). Int. J. Food Microbiol. 165, 312-318. doi: 10.1016/j.ijfoodmicro.2013.06.001

Dong, H., Cheng, L., Tan, J., Zheng, K., and Jiang, Y. (2004). Effects of chitosan coating on quality and shelf life of peeled litchi fruit. J. Food Engin. 64, 355-358. doi: 10.1016/j.jfoodeng.2003.11.003

dos Santos, N. S. T., Aguiar, A. J. A. A., Oliveira, C. E. V., Sales, C. V., Silva, S. M., Silva, R. S., et al. (2012). Efficacy of the application of a coating composed of chitosan and Origanum vulgare L. essential oil to control Rhizopus stolonifer and Aspergillus niger in grapes (Vitis labrusca L.). Food Microbiol. 32, 345-353. doi: 10.1016/j.fm.2012.07.014

Feng, W., Chen, J., Zheng, X., and Liu, Q. (2011). Thyme oil to control Alternaria alternata in vitro and in vivo as fumigant and contact treatments. Food Cont. 22, 78-81. doi: 10.1016/j.foodcont.2010.05.010

Feng, W., and Zeng, X. (2007). Essential oils to control Alternaria alternata in vitro and in vivo. Food Cont. 18, 1126-1130. doi: 10.1016/j.foodcont.2006.05.017

Gol, N. B., Patel, P. R., and Ramana Rao, T. V. (2013). Improvement of quality and shelf-life of strawberries with edible coatings enriched with chitosan. Postharv. Biol. Technol. 85, 185-195. doi: 10.1016/j.postharvbio.2013.06.008

Guo, H., Wu, B., Peng, X., Wang, J., Li, Q., Jin, J., et al. (2014). Effects of chlorine dioxide treatment on respiration rate and ethylene synthesis of postharvest tomato fruit. Postharvest Biol. Tec. 93, 9-14. doi: 10.1016/j.postharvbio.2014.01.013

Hong, K., Xie, J., Zhang, L., Sun, D., and Gong, D. (2012). Effects of chitosan coating on postharvest life and quality of guava (Psidium guajava L.) fruit during cold storage. Scientia Horticult. 144, 172-178. doi: 10.1016/j.scienta.2012.07.002

Kitur, F. S., Saroja, N., Habibunnisa, M., and Tharanathan, R. N. (2001). Polysaccharide-based composite coating formulations for shelf-life extension of fresh banana and mango. Eur. Food Res. Technol. 213, 306-311. doi: $10.1007 / \mathrm{s} 002170100363$

Liu, J., Tian, S., Meng, X., and Xu, Y. (2007). Effects of chitosan on control of postharvest disease and physiological responses of tomato fruits. Postharvest Biol. Tec. 44, 300-306. doi: 10.1016/j.postharvbio.2006.12.019
Meng, X., Li, B., Liu, J., and Tian, S. (2008). Physiological responses and quality attributes of table grape fruit to chitosan prehavest spray and postharvest coating during storage. Food Chem. 106, 501-508. doi: 10.1016/j.foodchem.2007.06.012

Perdones, A., Sanchez-Gonzalez, L., Chiralt, A., and Vargas, M. (2012). Effect of chitosan-lemon essential oil coatings on storage-keeping quality of strawberry. Postharvest Biol. Technol. 70, 32-41. doi: 10.1016/j.postharvbio.2012.04.002

Pharmaceutical Codex. (1979). Monographie: Eucalyptol, 11th Edn. London: The Pharmaceutical Press.

Quiao, K., Wang, Z., Wei, H., Wang, Y., and Wang, K. (2015). Evaluation of chemical alternatives to methyl bromide in tomato crops in China. Crop Prot. 67, 223-227. doi: 10.1016/j.cropro.2014.10.017

Ramos-García, M., Bosquez-Molina, E., Hernadez-Romano, J., Zavala-Padilha, G., Torrés-Rojas, E., Alia-Tejacal, I., et al. (2012). Use of chitosan-based edible coatings in combinations with other natural compounds, to control Rhizopus stolonifer and Escherichia coli DH5 $\alpha$ in fresh tomatoes. Crop Prot. 38, 1-6. doi: 10.1016/j.cropro.2012.02.016

Sánchez-Domínguez, D., Ríos, M. Y., Castillo-Ocampo, P., Zavala-Padilla, G., Ramos-García, M., and Bautista-Baños, S. (2011). Cytological and biochemical changes induced by chitosan in the pathosystem Alternaria alternata-tomato. Pestic. Biochem. Physiol. 99, 250-255. doi: 10.1016/j.pestbp.2011.01.003

Snowdon, A. L. (1991). "Solanaceous fruit vegetables: tomatoes, pepper and eggplants," in A Color Atlas of Post-Harvest Diseases and Disorders of Fruits and Vegetables, ed. A. L. Snowdon (Ames, IA: Blackwell Publishing), 88.

Soylu, E. M., Kurt, S., and Soylu, S., (2010). In vitro and in vivo antifungal activities of the essential oils of various plants against tomato grey mould disease agent Botrytis cinerea. Int. J. Food Microbiol. 143, 183-189. doi: 10.1016/j.ijfoodmicro.2010.08.015

Tao, F., Zhang, L., McCarthy, M. J., Beckeles, D. M., and Saltveit, M. (2014). Magnetic resonance imaging provides spatial resolution of chilling injury in micro-tom tomato (Solanum lycopersicum L.) fruit. Postharvest Biol. Technol. 97, 62-67. doi: 10.1016/j.postharvbio.2014.06.005

Tian, J., Ban, X., Zeng, H., Huang, B., He, J., and Wang, Y. (2011). In vitro and in vivo activity of essential oil from dill (Anethum graveolnes L.) against fungal spoilage of cherry tomatoes. Food Cont. 22, 1992-1999. doi: 10.1016/j.foodcont.2011.05.018

Tian, J., Zeng, X., Lü, A., Zhu, A., Peng, X., and Wang, Y. (2015). Perillaldehyde, a potential preservative agent in foods: assessment of antifungal activity against microbial spoilage of cherry tomatoes. LWT-Food Sci. Technol. 60, 63-70. doi: 10.1016/j.lwt.2014.08.014

Tijjani, A., Adebitan, S. A., Gurama, A. U., Aliyu, M., Harunam, S. G., Mohammad, G. U., et al. (2014a). Invitro and Invivo efficacy of some plant extracts for the control of tomato fruit rot caused by Aspergillus flavus. Int. J. Sci. Res. Public. 4, $1-5$.

Tijjani, A., Adebitan, S. A., Gurama, A. U., Haruna, S. G., and Safiya, T. (2014b). Effect of some selected plant extracts on i, a causal agent of fruit rot disease of tomato (Solanum lycopersicum) in Bauchi State. Int. J. Biosci. 4, 144-252.

Vargas, M., Pastor, C., Chiralt, A., McClements, D. J., and González-Martínez, C. (2008). Recent advances in edible coatings for fresh and minimally-processed fruits. Crit. Rev. Food Sci. 48, 496-511. doi: 10.1080/10408390701537344

World Processing Tomato Council [WPTC]. (2010). Minutes of the WPTC meeting (Paris on 18 October 2010). Available at http://www.wptc.to/pdf/ meetings/meeting84.pdf

Conflict of Interest Statement: The authors declare that the research was conducted in the absence of any commercial or financial relationships that could be construed as a potential conflict of interest.

Copyright (C) 2015 de Souza, Sales, de Oliveira, Lopes, da Conceição, Berger and Stamford. This is an open-access article distributed under the terms of the Creative Commons Attribution License (CC BY). The use, distribution or reproduction in other forums is permitted, provided the original author(s) or licensor are credited and that the original publication in this journal is cited, in accordance with accepted academic practice. No use, distribution or reproduction is permitted which does not comply with these terms. 